\title{
O DISCURSO DA MÍDIA SOBRE A RESISTÊNCIA INDÍGENA NA AMAZÔNIA
}

\section{THE DISCOURSE OF MEDIA ON INDIGENOUS RESISTANCE IN THE AMAZON}

\author{
Alessandro Nobre Galvão ${ }^{1}$
}

\begin{abstract}
RESUMO: Neste trabalho, propomos o exame dos sentidos que circularam na mídia tradicional sobre o gesto da índia Tuíra, por ocasião do I Encontro dos povos indígenas da Amazônia, em 1989. Para tal, traçamos a conjuntura sócio-histórica que desembocou no fato contingente, qual seja, o toque do facão da índia no rosto do representante da Eletronorte, José Antônio Muniz Lopes. Discutiremos como a grande mass media, que cobriu o evento, à época, trabalhou para estancar qualquer possibilidade do vir a ser diferente, do sentido outro que pudesse fazer a memória discursiva estilhaçar-se em seu funcionamento. O corpus discursivo é constituído por materialidades discursivas de natureza semiótica diferenciada, quais sejam, a célebre foto que capturou a cena histórica da índia Tuíra tocando com seu facão a face do ex-diretor da Eletronorte José Antônio Muniz Lopes e um recorte de uma matéria jornalística que, à época, tematizou tal cena enunciativa.
\end{abstract}

PALAVRAS CHAVE: discurso da mídia; resistência indígena; desentendimento

\begin{abstract}
In this work, we propose an examination of the meanings disseminated by the traditional media about the gesture of Tuira, on the occasion of the I Meeting of the indigenous peoples from the Amazon, in 1989. To this end, we trace the socio-historical situation that led to the contingent fact, namely, the touch of the Indian machete on the face of the Director of Eletronorte, José Antônio Muniz Lopes. We will discuss how the great mass media, which covered the event, at the time, worked to stop any possibility of the different, the possibility of another meaning that could make the discursive memory shatter in its functioning. The discursive corpus consists of discursive materialities of a different semiotic nature, that is, the famous photo that captured the historical scene of the Tuira, touching with her machete the face of the former director of Eletronorte José Antônio Muniz Lopes and an extract of a journalistic article that, at the time, thematized such enunciative scene.
\end{abstract}

KEY WORDS: media discourse; indigenous resistance; mutual misunderstanding

\section{Introdução}

\footnotetext{
${ }^{1}$ Doutor em Linguística pela UFPA com Doutorado Sanduíche na UFRGS. Professor da UFPA. Projeto com apoio da Universidade Federal do Pará; Universidade Federal do Rio Grande do Sul; Cnpq e Prof. Dra Freda Indursky.
} 
Este trabalho debruça o olhar sobre a conjuntura sócio-histórica que antecede a emergência de um discurso novo na ordem dos discursos sobre a gestão dos recursos naturais na Amazônia brasileira - o discurso de recusa radical ao Complexo Hidrelétrico de Belo Monte (CHBM). Mais especificamente, objetivamos examinar como a imprensa tradicional brasileira trabalhou os sentidos de um fato histórico: o gesto de revolta da índia Tuíra durante o I Encontro dos povos indígenas em 1989. A nosso ver, este foi o evento que permitiu a emergência e circulação desse discurso que, por razões de tempo e espaço, não será objeto de análise deste artigo.

O corpus discursivo é constituído por materialidades discursivas de natureza semiótica diferenciada, quais sejam, a célebre foto que capturou a cena histórica da índia Tuíra tocando com seu facão a face do ex-diretor da Eletronorte José Antônio Muniz Lopes e um recorte de uma matéria jornalística que, à época, tematizou a cena enunciativa

Nosso gesto analítico se inscreve no quadro teórico da Análise de discurso francesa de vezo pecheutiano (doravante $\mathrm{AD}$ ) ao partirmos do pressuposto de que o discurso "efeito de sentido entre interlocutores" é um construto teórico em que se pode analisar a relação entre língua, história e ideologia (elemento que, pelas relações de forças instaladas no seio de uma dada formação social, produz a determinação histórica dos processos semânticos).

\section{Condições sócio-históricas para o trabalho dos sentidos sobre a resistência indígena}

A compreensão do quadro conjuntural mais amplo no qual se localiza o fato histórico de que ora nos ocupamos necessita um pequeno retrospecto histórico. Realizado em 1989, o I Encontro dos Povos Indígenas do Xingu em Altamira-Pará, organizado pelas principais lideranças indígenas Kaiapó da região do Xingu e com o apoio de organizações ativistas como o Centro Ecumênico de Documentação (Cedi) ${ }^{2}$, ocorreu um ano após a decisão do Tribunal Federal de Recursos decidir pelo trancamento da ação penal ${ }^{3}$ movida pela Procuradoria Geral da República contra os líderes Indígenas Kaiapó Paulinho Paiakan Kube-I e um ano após a aprovação, pelo Departamento Nacional de Águas e Energia (DENAAE) ${ }^{4}$, do relatório final de inventário hidrelétrico da bacia hidrográfica do rio Xingu.

\footnotetext{
${ }^{2}$ Organização que mais tarde originaria o Instituto Sócio Ambiental (ISA).

${ }^{3}$ Em evento acadêmico ocorrido em duas universidades importantes dos EUA, os líderes indígenas denunciaram o projeto do Governo Federal brasileiro, com o apoio do Banco Mundial (BIRD), em promover o aproveitamento hidrográfico do rio Xingu, instalando uma grande hidrelétrica e pequenas centrais hidrelétricas, o que ocasionaria a inundação de sete milhões de hectares desalojando 13 grupos indígenas. Com base nesses relatos, a Procuradoria Geral da República formaliza denúncia contra os representantes indígenas enquadrando-os na lei dos estrangeiros.

${ }^{4}$ Extinto órgão regulador do setor energético brasileiro. 
No evento, participaram cerca de três mil pessoas, dentre as quais figuraram, como ideologicamente alinhados à causa indígena, 650 indígenas do Brasil e de outras partes do mundo, 300 ambientalistas e uma personalidade artística internacional, o cantor britânico Sting. Do lado oposto, participaram o então presidente da Eletronorte José Antônio Muniz Lopes, o então presidente do Instituto Brasileiro do Meio Ambiente e dos Recursos Renováveis (IBAMA) Fernando César Mesquita. Ainda participaram um grupo de autoridades locais tais como vereadores e o prefeito da cidade de Altamira, um grupo de deputados federais, bem como pessoal da imprensa nacional e internacional.

Considerando a implementação de barragens no rio Xingu, pelo Governo Federal, uma realidade iminente, os líderes indígenas exigiam dos principais representantes do governo, presentes no encontro, uma explicação sobre a não consulta aos povos indígenas sobre o destino do rio Xingu e mais, um esclarecimento sobre os contornos do projeto de construção do complexo hidrelétrico do Xingu.

\section{A natureza do conflito: formações sociais em confronto e o desenho de formações discursivas antagônicas.}

O fato histórico, trabalhado pelo olhar da mass mídia, remete a um conflito entre índios e brancos. Considerando o fato de que os índios estão excluídos ou não têm lugar na formação social capitalista, pensamos numa primeira relação de confronto que se desenrola entre formações sociais diferentes no que tange à aceitação ou defesa do projeto Belo Monte. Se falamos em confronto, é porque consideramos o fato de que em ambas formações sociais os recursos naturais são entendidos, portanto, significados de forma diferenciada, havendo aí um marcante ruído. Essa é uma questão que precisa ser problematizada a partir do gesto de interpretação indígena sobre sua relação com esses recursos. Convocamos aqui o conceito althusseriano de ideologia e suas teses centrais que o ressignificam a partir dos textos de Marx. Tais teses esclarecem: 1) a ideologia "representa a relação imaginária do indivíduo com suas reais condições de existência" (ALTHUSSER, 1983, p. 77); 2) a ideologia é dotada de uma existência material.

Essas considerações nos permitem pensar que o modo de existência das sociedades Kayapós, marcado especificamente por práticas de subsistência e que constitui sua formação social-econômica não são acessíveis diretamente pelo sujeito indígena, mas sim que essas 
mesmas práticas e as relações que dela derivam são (re)produzidas como um imaginário que se representa na ideologia.

Com vistas à sustentação de nosso ponto de vista, trazemos aqui um recorte da “Declaração de Altamira” publicada em Ricardo (1981, p. 335), um texto produzido pelas lideranças indígenas presentes no I Encontro acima mencionado.

\section{a) Nossos territórios são os sítios sagrados de nosso povo, morada de nosso criador que não podem ser violados.}

Nesta sequência discursiva (SD), a violação de sítios sagrados (os rios e as florestas) profana o sagrado. Atestamos um entrelaçamento do discurso mítico indígena (que atribui aos elementos da natureza o status de entidades sagradas) com o discurso da subsistência indígena (que identifica nesses elementos a continuidade da vida de um povo). O resultado desse entrelaçamento discursivo se materializa no uso de termos como "violação" quando se trata das ações radicais de exploração que modificam a característica natural dos rios e das florestas, mas também na performatização de rituais como o que se verá capturado na foto da índia Tuíra analisada adiante.

Neste ponto de nossa reflexão, podemos resumir o que segue: o conflito que se desenrola entre a formação social indígena e a formação social capitalista, no que concerne ao problema da instalação do CHBM no rio Xingu, tem a ver com os modos distintos como os recursos naturais tem seu lugar no seio de cada formação. No primeiro caso, a demanda do índio é pela subsistência do grupo coletivo a partir dos produtos que naturalmente o meio lhe proporciona. Trata-se de uma relação conservadora 5 . Já no segundo caso, a demanda do sujeito branco é pela geração de riquezas a partir do aproveitamento dos recursos naturais de modo a constituí-los em mercadoria. Trata-se de uma relação transformadora. Esses modos distintos de relacionar-se com o meio são objetos produzidos na/pela relação imaginária dos sujeitos com suas reais condições de existência que se fazem perceber nas formações ideológicas dominantes em cada formação social. As ideologias materializam-se em formações discursivas ${ }^{6}$ (FD) também distintas. No caso do sujeito indígena, este tomará posição em uma FD cujos saberes significam o rio e a floresta como a morada do sagrado e a fonte de subsistência (portanto, a

\footnotetext{
${ }^{5} \mathrm{O}$ que estamos designando como relação conservadora passa pelo entendimento da manutenção/conservação da natureza em seu estado natural, isto é, sem estabelecer com ela uma relação depredadora e destrutiva.

${ }^{6}$ Uma FD impõe ao sujeito o que pode e o que não pode ser dito. No dizer de Pêcheux ([1975]/2009, p. 147) "as palavras, expressões, proposições recebem seus sentidos da FD na qual são produzidas". 
floresta, o rio é vida e precisam ser conservados em seu estado natural). Chamaremos essa FD de formação discursiva da subsistência indígena (FDSI). No caso do sujeito branco, este tomará posição em uma FD cujos saberes significam, mais especificamente o rio, como fonte de geração de energia elétrica (portanto o rio é uma via estratégica para o desenvolvimento do país). Designaremos essa FD de formação discursiva desenvolvimentista do branco (FDDB).

\section{Um lugar de memória: o gesto e a produção de sentidos}

O inesperado pelos espectadores ocorreu no segundo dia do encontro, no exato momento em que Muniz Lopes estava com a palavra. Ele seguia apresentando as características do projeto, as vantagens e as medidas tomadas pelo governo no sentido de mitigar os impactos do empreendimento no rio Xingu. A jovem Tuíra, subitamente, se aproxima do engenheiro e, com seu facão, realiza movimentos cortando o ar, ao mesmo tempo em que produz um texto em sua língua materna ${ }^{7}$. Finaliza sua performance pressionando o terçado com força sobre a maçã do rosto do então diretor da Eletrobrás, que se manteve paralisado, com os olhos fechados e os braços cruzados sobre a bancada. Este momento é capturado pelas câmeras dos fotógrafos de diversos veículos de imprensa:

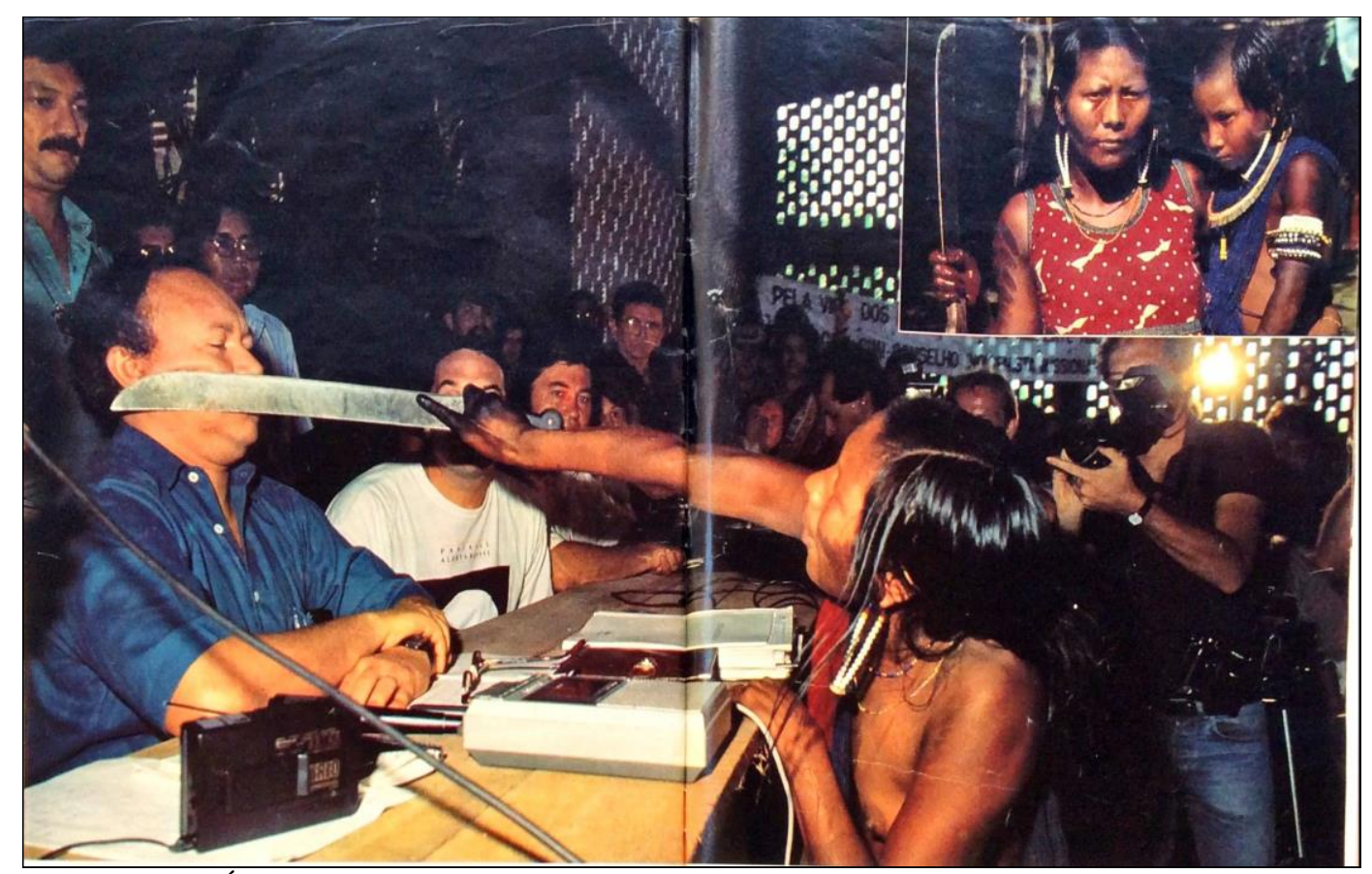

Fotografia 1 - Índia Tuíra toca o facão no rosto do presidente da Eletrobrás, Muniz Lopes

\footnotetext{
${ }^{7}$ Para este trabalho, não nos convém transcrever este texto verbal. Sabemos que seu conteúdo sustenta o rechaço à barragem tanto quanto o facão no rosto de Muniz Lopes. 
Nosso olhar lançado sobre essa foto busca interpretá-la enquanto uma materialidade discursiva cuja natureza semiótica imagética é opaca. Perguntamo-nos sobre os sentidos que essa foto pode produzir e para responder essa pergunta é necessário um exame detalhado do que é dado a ver nesta cena enunciativa. Primeiramente, vamos refletir sobre os lugares sociais ocupados por esses sujeitos que se apresentam na cena enunciativa capturada pela foto. Como podemos perceber, estes sujeitos discursivos se identificam com lugares sociais inscritos na estrutura de formações sociais radicalmente diferentes. E se estamos entendendo desse modo, a interlocução entre os polos A e B resulta naquilo que Mangueneau (1989, p. 119-20) chama de zona de interincompreensão constitutiva. Isto porque o processo da interlocução é marcado pelo desentendimento, que nos termos de Ranciere (1996) diz respeito a

um tipo determinado de situação de palavra: aquela em que um dos interlocutores ao mesmo
tempo entende e não entende o que diz o outro. O desentendimento não é o conflito entre aquele
que diz branco e aquele que diz preto. É o conflito entre aquele que diz branco mas não entende
a mesma coisa, ou não entende de modo nenhum que o outro diz a mesma coisa com o nome
de brancura. (p11).

E por que há desentendimento na cena enunciativa em análise? Porque identificados a lugares sociais estruturados em formações sociais distintas, os sujeitos falam dos mesmos objetos, mas não entendem tratar-se das mesmas coisas. De maneira mais específica, os sujeitos se referem ao mesmo recurso natural, o rio Xingu, mas não compreendem que é a mesma coisa figurando em suas falas, pois a interpretação do referente ou objeto discursivo não coincide. Com respeito ao tipo de interlocução que se processa entre o sujeito discursivo que representa o poder constituído (o Estado) e o sujeito discursivo que representa o segmento indígena, podemos dizer tratar-se de uma interlocução discursiva simulada pois a cena enunciativa se constitui a partir do simulacro da visibilidade mútua entre as partes. Vejamos o porquê disso.

O artigo 231 da Constituição Federal de 1988 determina que os povos indígenas do Brasil detêm a posse das terras que tradicionalmente habitam além, é claro, dos recursos que nelas estão presentes. Como está previsto no $\S 5^{\circ 8}$ deste mesmo artigo, salvo em casos excepcionais, o congresso nacional via "Ad Referendum" pode deliberar sobre a remoção desses povos, processo transitório tão logo o impeditivo da permanência dos indígenas se

\footnotetext{
${ }^{8} \S \mathbf{5}^{\mathbf{0}}$ É vedada a remoção dos grupos indígenas de suas terras, salvo, "ad referendum" do Congresso Nacional, em caso de catástrofe ou epidemia que ponha em risco sua população, ou no interesse da soberania do País, após deliberação do Congresso Nacional, garantido, em qualquer hipótese, o retorno imediato logo que cesse o risco. 
resolva. Portanto, o texto constitucional coloca barreiras claras para a exploração dos recursos naturais presentes nas terras tradicionalmente habitadas pelos povos indígenas, e, caso haja interesse do Estado em explorá-las, há que primeiramente obter-se a anuência formal desses povos, caso contrário tal ato constitui violação dos direitos constitucionalmente conquistados pelos indígenas.

No que se refere ao I Encontro de 89, o Estado brasileiro, representado pela figura do presidente da Eletrobrás, Muniz Lopes, vê-se obrigado a atender o chamado dos índios para dar explicações sobre o projeto de barrar o rio Xingu. De fato, todo o ritual formal do encontro é estabelecido, pois é dado um lugar de destaque para este presidente falar, mas o mesmo processo prevê que ele também escute os povos impactados pelo empreendimento. Aqui reside o aspecto que estamos problematizando: aos índios é conferido, pelo Estado, uma posição de escuta somente, pois apesar de o I Encontro promover um processo de interlocução ativo entre este segmento e o representante do Estado, a cena enunciativa que se desenrola nos demonstra que há um apagamento de um dos polos da interlocução, no caso o dos índios, pois a palavra é dada apenas ao polo A, cabendo ao B apenas ouvir.

Sobre essa questão, os estudos de Silveira (2010), ao examinar discursivamente uma decisão judicial acerca da delimitação da Reserva Indígena Raposa Serra do Sol, pelo Supremo Tribunal Federal, pode nos dar uma luz. A autora constatou que na constituição imaginária do sujeito brasileiro, o índio nunca aparece como fazendo parte dela, mas sim como um elemento estrangeiro, ou, um "outro" do brasileiro. Isto tem implicações no modo como, por exemplo, nos discursos que circulam no social, produz-se o efeito de evidência de que o Estado do branco impõe a História, o poder, cabendo aos sujeitos índios acatar decisões. Há, nos termos de Silveira (2010) uma espécie de apagamento da cultura indígena. Os povos indígenas são constantemente discursivizados como sujeitos menores e incapazes cuja tutela legal pertence ao Estado brasileiro. Este pré-construído sobre a menoridade indígena historicizou-se como sentido socialmente possível inscrito no Interdiscurso a partir da promulgação da Lei $\mathrm{n}^{\circ} 3.071$, de $1^{\circ}$ de janeiro de 1916 - Código Civil - que, em seu artigo $6^{\circ}$, inciso IV, elenca os aborígenes como relativamente incapazes, sujeitando-os, em seu parágrafo único, ao regime tutelar, estabelecido em leis e regulamentos especiais, e que cessará à medida de sua assimilação à cultura dominante do branco. Percebe-se como historicamente o Estado brasileiro silenciou os índios e suas culturas, apesar dos esforços da constituinte de 88 em reconhecer a especificidade das mesmas. 
É este imaginário do índio como menor que funciona na base do processo de interlocução capturado pela foto em análise. Como dissemos, a cena enunciativa simula uma interlocução simétrica entre os polos A e B, visto que o texto constitucional assim o determina, no entanto, sabemos que o polo A que representa o poder de Estado não ouve o polo B. Podemos nesse passo trazer Ranciére (1996) para iluminar nossa reflexão. O autor nos esclarece sobre os lugares determinados para cada grupo de sujeitos no social, o que ele chama de a partilha do sensível:

\begin{abstract}
Há distribuição simbólica dos corpos, que os divide em duas categorias: aqueles a quem se vê, os de quem há um logos - uma palavra memorial, uma contagem a manter - e, aqueles acerca dos quais não há logos, os que falam oralmente e aqueles cuja voz, para exprimir prazer e dor, apenas imita a voz articulada. Há política porque o logos nunca é apenas a palavra: a contagem pela qual uma emissão sonora é ouvida como palavra, apta a enunciar o justo, enquanto uma outra é apenas percebida como barulho que designa prazer ou dor, consentimento ou revolta (p.36).
\end{abstract}

Esta passagem nos ajuda a pensar na razão pela qual a cena enunciativa se processa na base da simulação, pois o sujeito índio não apresenta um logos e não representa uma contagem na partilha do sensível. Esta condição de invisibilidade indígena não é a que o texto constitucional prevê, entretanto, na prática, o Estado do branco opera com o imaginário do sujeito índio menor, incapaz, selvagem e fadado ao desaparecimento caso não se misture à cultura do branco. Tanto é assim que, mais uma vez, retornando ao trabalho de Silveira (2010) sobre a decisão judicial que examinou, constatou-se que os índios não constavam no processo com algum poder de decisão, apenas como partes interessadas. Ou seja, em termos rancierianos, os índios não representam uma contagem pois de suas bocas só é possível ouvir ruídos.

De tudo quanto foi exposto, cabe-nos uma reflexão sobre o que o gesto da índia, naquela foto, pode significar, levando-se em consideração o aspecto já discutido sobre a não contagem dos sujeitos índios pelo Estado do branco. Para tanto, vamos convocar aqui as considerações de Zizek (1999) sobre o sintoma social:

O 'sintoma' estritamente falando é um elemento particular que subverte seu próprio fundamento universal, uma espécie que subverte seu gênero. Nesse sentido, podemos dizer que o método marxista elementar da crítica da ideologia já é sintomático: ele consiste em detectar um ponto de ruptura heterogêneo para um dado campo ideológico e, ao mesmo tempo, necessário para que esse campo consiga seu fechamento, na forma acabada (p. 306). 
E o que é sintomático no gesto indígena do facão roçando o rosto de uma autoridade designada pelo Estado para defender um mega projeto de barragem do rio Xingu? Ora, este gesto só pode indicar um ponto de ruptura heterogêneo para um dado campo ideológico, isto é, a tão propalada garantia constitucional do direito indígena à diferença (reconhecimento de sua especificidade cultural, econômica e religiosa), do direito indígena à voz e poder de decisão em instâncias jurídicas não passa de um engodo. Do mesmo modo como Zizek (1999) nos mostra em sua reflexão sobre o modo como o universalismo dos direitos e deveres burgueses, a ideia de que todos são livres, quando de fato permanece recalcada as relações de dominação e servidão entre os homens (sintoma social), podemos dizer que o gesto indígena do facão aponta para um sintoma social: o aspecto heterogêneo do tratamento que o Estado dá aos grupos indígenas que os converte em menores e necessitados de tutela estatal. Como menores, sua voz não é ouvida, sua cultura é menor e desprezada. O toque do facão é também um sintoma de que aquela interlocução só pode ser entendida como um simulacro, pois toda ela é atravessada pelo desentendimento, dado que desde a gênese o Estado do branco não escuta o índio porque não o enxerga como capacitado para a interlocução, não entende de que objetos fala. Aquele facão institui um dano, isto é, um enfrentamento que subverte a contradição de dois mundos alojados num só (RANCIERE, 1996).

Esta contradição e o que dela resulta (desentendimento entre interlocutores determinados por formações sociais radicalmente opostas) que se mostra na materialidade fotográfica em exame nos permite dizer que há nela a captura de dois discursos em relação de confronto. Desse modo, compreendemos o gesto da índia como uma materialidade ritual que toma corpo na/pela formação ideológica que domina a formação social indígena. Pelo processo da interpelação ideológica, o sujeito é conduzido a ocupar seu lugar, neste caso, de defensor aguerrido da mata e do rio. Portanto, o sujeito ergue seu facão e afronta o inimigo, este que segue intentando profanar a morada do sagrado com a proposição de um complexo hidrelétrico. Dito de outro modo, este sujeito se identifica com uma posição de sujeito alinhada a uma formação discursiva cujos saberes apontam para o rio Xingu como fonte da vida. Consideramos o toque do facão como a materialidade discursiva da resistência indígena a qualquer tentativa de barrar o rio Xingu.

\section{Trabalho dos sentidos na imprensa brasileira sobre o inusitado}


A análise da materialidade fotográfica que capturou o discurso indígena nos permite agora avançar um pouco mais em nossas observações, desta vez, pensando mais detidamente sobre o trabalho dos sentidos na imprensa brasileira de referência para conter a possibilidade de irrupção do diferente. Mais uma vez, por questões de espaço, vamos examinar apenas um recorte de matérias jornalísticas dos principais representantes da mídia tradicional impressa que versavam, à época, sobre a cena inusitada do facão. No caso desse artigo, selecionamos, como sequência discursiva de referência ${ }^{9}$ (Sdr), um recorte da reportagem de O liberal (LB) por meio do qual pudemos flagrar a produção de gestos de interpretação sobre a atitude da índia. Não podemos deixar de salientar que a seleção desse material implica um trabalho com uma dupla discursiva, a saber, o discurso de e o discurso sobre que já foi objeto de inúmeros trabalhos de Indursky sobre o Movimento dos Trabalhadores Sem Terra. Com base em Indursky (2000), entendemos que o discurso de é identificável nos fragmentos de discurso relatado indireto que marcam uma posição de sujeito abrigada na FD da subsistência indígena. Os discursos sobre, nos termos de Mariani (1996), "são discursos intermediários, pois, ao falarem sobre um discurso, situam- se entre este e o interlocutor, qualquer que seja ele". O discurso jornalístico é classificado por esta autora como uma modalidade de discurso sobre. Ele pode ser pensado como uma modalidade em que o locutor se auto-institui como intermediário pretensamente imparcial ${ }^{10}$ entre, no nosso caso, os sujeitos do dissenso e a opinião pública.

Retornando à questão do inusitado, vamos considerar que do lado dos expectadores que testemunharam o gesto súbito da índia, instalou-se uma inquietação muito forte, pois aquilo reclamava sentidos.

Nas considerações de Indursky (2003), o acontecimento histórico reclama sentidos, precisa ser discursivizado, mas antes que os sentidos sejam formulados é preciso haver intervalos, dando lugar ao silêncio, cujo "contínuo significante” será preenchido pouco a pouco pela palavra. É com este silêncio que estamos compreendendo a (falta de) reação dos participantes, o olhar surpreso e atento ao fato novo: mas o que é isto que está ocorrendo?

Nessa pesquisa, aventamos a hipótese de que o trabalho dos sentidos na/pela imprensa tradicional conduziu uma leitura hegemônica do gesto de Tuíra, o que se agarrou na memória discursiva. O que estamos dizendo é que a memória discursiva determina as leituras possíveis

\footnotetext{
${ }^{9}$ Esta é uma noção forjada por Courtine (1981) que tem por função representar o fato discursivo que se alastra no corpus discursivo do analista. É, portanto, uma noção metodológica que visa tornar operacionalizável o trabalho com uma série de outras Sdr que repetem o mesmo fato discursivo em exame

${ }^{10}$ Como veremos mais à frente nas Sdr recortadas, há um desequilíbrio se compararmos o pouco espaço dado à versão indígena sobre o significado do gesto de Tuíra e o amplo espaço dado à versão do branco sobre o significado deste mesmo gesto.
} 
para a imagem da índia com seu facão, isto é, institui o processo discursivo que determina a direção dos sentidos a serem lidos a partir de seu gesto de interpretação. Consideramos, pois, em consonância com o estudo de Souza ${ }^{11}$ (2001) que essas narrativas jornalísticas pretendem indicar para o leitor "em que posição ele deve se colocar na ordem simbólica social e política em meio a outros leitores e leituras possíveis" (p. 4). Nosso intento, a partir desta premissa teórica, é mostrar o esforço do discurso midiático no sentido de estancar sentidos diferentes que poderiam perturbar a memória social em circulação e consequentemente irromper no acontecimento discursivo $^{12}$. Como veremos na matéria em exame, não há destaque para a a posição de sujeito dos índios Kayapós, o que nos leva a constatar que a mídia, de modo geral, identifica-se com a posição de sujeito dominante na FDDB fazendo ressoar a memória social do colonizador que abriga sentidos pré-estabelecidos sobre a conduta histórica do índio: não há nada de novo sob o sol.

\section{Versões para o fato histórico: a significação do corpo indígena como selvagem}

Indursky (2003) compreende a estrutura em duas dimensões, a saber, a vertical e a horizontal. A primeira comporta o conjunto dos saberes pré-existentes ao discurso do sujeito. Esses saberes, como já dissemos, são entendidos como enunciados pré-construídos cuja morada é uma FD e antes dela o interdiscurso, que fazem retorno no/sobre o dizer do sujeito. Vale a pena reforçar com o que a autora sistematiza:

(...) ao inscrever seu discurso na ordem da repetibilidade, o sujeito produz um duplo movimento. Inicialmente retira seu discurso de uma rede de formulações pré-existentes (COURTINE, 1981) e, ato contínuo, re-inscreve seu dizer nesta mesma rede de formulações. Ou seja: os saberes originam-se na rede de formulações e a ela retornam, instituindo uma espécie de moto perpétuo ou, se preferirmos, um ciclo de repetibilidade. (INDURSKY, 2003, p. 103)

A segunda estrutura corresponde à rede de formulações ou intradiscurso. A formulação retira o enunciado de lá da estrutura vertical em sua condição de-sintagmatizada para linearizálo ou atualizá-lo, o que poderá, nesse "ponto de encontro" entre as duas dimensões inter e

\footnotetext{
${ }^{11}$ Souza nos explica que as legendas cumprem esse papel de indicar ao leitor a posição que ele deve se colocar na ordem simbólica social e política para ler as imagens a que tais legendas se referem. Diríamos, pois, que as narrativas jornalísticas também conduzem o gesto de interpretação do leitor.

${ }^{12}$ Nos termos de Pêcheux ([1983a]/2006), o acontecimento discursivo se constitui como ponto de encontro entre uma atualidade e uma memória. 
intradiscursiva, incorrer na repetição do mesmo ou na irrupção do diferente, tudo isso regido pelo efeito de memória (pela atualização, os sentidos podem ser repetidos ou re-significados).

Diante do exposto, não podemos negar o estatuto do discurso como estrutura, uma vez que a formulação do sujeito faz retorno no já-la dos sentidos, no enunciado pré-construído, permitindo que o moto-contínuo da repetibilidade se instale. Ao mesmo tempo, pelo fato de a estrutura abrigar a possibilidade de equivocidade, de o efeito de memória "ser fortemente lacunar permitindo que os sentidos deslizem, derivem, se transformem, se re-signifiquem" (INDURSKY 2003, p. 104), o discurso é acontecimento. Em suma,

(....) a memória tende a absorver o acontecimento, como uma série matemática, e prolonga-se, conjecturando o termo seguinte, em vista do começo da série, mas o acontecimento discursivo, provocando interrupção, pode desmanchar essa regularização e produzir retrospectivamente uma outra série que não estava, enquanto tal, e que é assim o produto do acontecimento; o acontecimento, no caso, desloca e desregula os implícitos associados ao sistema de regularização anterior (PÊCHEUX, [1983b]/2010, p.52).

Retornemos ao fato histórico sob análise, capturado pelas lentes das câmeras fotográficas presentes no I Encontro. Uma grande quantidade de espectadores fixou a atenção mais sobre o que a índia fazia, menos sobre o que falava. De pronto, o gesto de interpretar a performance da índia, descolando-o do texto verbal, por falta, é claro de inteligibilidade, potencializou a equivocidade do acontecimento.

Por mais equívoco que se constitua o acontecimento histórico, há sempre um trabalho de negação que busca atá-lo à rede dos enunciados já estabilizados, buscando sufocar os sentidos que respiram à margem. A imprensa tradicional brasileira, assumindo o papel enunciativo de narradora do fato ocorrido durante o I Encontro de 88, demonstra-nos a posição de sujeito que assume no tocante ao litígio estabelecido entre o branco e o índio. Há uma clara inscrição do sujeito das narrativas jornalísticas na FDDB, uma vez que este sujeito trabalha no discursivo reafirmando os sentidos pré-significados na memória discursiva sobre a ação indígena. Vejamos a Sdr e a análise subsequente:

(SD) O LIBERAL - 22/02/1989 - reportagem/narrativa dos fatos ocorridos no I encontro dos povos indígenas de 1989: como autoridades de governo, é possível que Fernando César Mesquita, presidente do Instituto de Meio Ambiente, representando o presidente Sarney, e José Antônio Muniz Lopes, diretor de planejamento e operações da Eletronorte, jamais tenham passado por um momento tão constrangedor, e perigoso, quanto o vivido ontem de manhã no Centro Comunitário de Altamira. $O$ representante da Eletronorte dava explicações sobre o projeto da barragem Kararaô, quando a índia Tu-Ira, do alto Xingu, levantou do meio do salão e cortou a palestra ao meio quase cortando as orelhas das duas autoridades. 


\begin{abstract}
"Mentira, sua história não vale nada. Porque não vai dizer a verdade lá na nossa aldeia?" esbravejou Tu-Ira na língua dos Kaiapó. Ato contínuo, suspendeu o facão que tinha nas mãos e começou a passá-lo a poucos centímetros da cabeça de Muniz representante de Sarney. Durante um longo minuto a lâmina ia e vinha abanando os pescoços e cabeças oficiais. Apreensão, perplexidade e medo estiveram presentes naquele momento. Da arquibancada do Centro Comunitário vinham gritos "corta, corta".
\end{abstract}

Uma análise global da Sdr nos permite compreender o processo de discursivização do "real" pelo olhar da grande mass media. Este "real" que como afirma Pêcheux ([1983a]/2006, p. 43) diz respeito a um "saber que não se transmite, não se aprende, não se ensina, e que, no entanto, existe produzindo efeitos". Quer dizer, o fato contingente, o inusitado de que já falamos irrompe como "o impossível de falar, de descrever, de relatar, de produzir um sentido único" (FERNANDES, 2008 p. 40), mas que impõe sua presença como um inevitável a ser simbolizado. A mídia, por meio do recorte de parte do "real", operado pelo imaginário, transforma o produto desta operação em uma realidade cujos objetos de saber encontram lugar num universo discursivo logicamente estabilizado: o que se pode esperar do índio senão sua incapacidade de dialogar e sua disposição para agredir? Reparemos que o corte no real produzido e dado a circular em seu aspecto discursivo pelas narrativas da imprensa permite que se enxergue o evento por duas perspectivas tratadas pelo filtro ideológico da FDDB: a cena enunciativa focada nos sujeitos Muniz Lopes - Tuíra e a cena discursiva focada na ação da índia. É sob a égide dessas duas perspectivas que podemos organizar as paráfrases oriundas da SD em foco:

\begin{tabular}{|l|l|}
\hline A cena enunciativa & A cena discursiva \\
\hline $\begin{array}{l}\text { Momento de constrangimento e perigo. } \\
\text { Momento de apreensão, perplexidade e } \\
\text { medo. }\end{array}$ & A \\
\hline
\end{tabular}

Quadro 1 - gestos de interpretação determinados pela FDDB

Os dizeres da imprensa sobre o fato contingente contornam parte do "impossível", a parte que dá a ver o sentimento e a avaliação do branco sobre a cena que se processa entre os sujeitos do dissenso. O locutor da Sdr em análise desloca o foco do discurso para a sensação experimentada pelas autoridades diante da ação e do gesto de Tuíra. Do lado das autoridades, mais particularmente do de Muniz-Lopes, imperou o constrangimento e o medo pela iminente 
possibilidade de ser golpeado. Em entrevista concedida à revista Manchete (1989, p. 113), este sujeito afirma o que segue: "Tenho contato com os índios desde 1979 e já vivi situações piores. Mas se dissesse que não tive medo estaria mentindo".

Perguntamo-nos sobre o que sustenta este gesto de interpretar o toque do facão como algo de selvagem e temeroso. Reformulando a questão: que pré-construídos abrigados na memória discursiva do colonizador foram acionados pela FDDB (que determina o discurso desse sujeito e da mídia impressa) quando do trabalho de absorção/apagamento do acontecimento discursivo?

Esse gesto de interpretação do sujeito que experienciou o toque do facão indígena faz retorno sobre a memória que sedimentou no imaginário do brasileiro os saberes relativos aos primeiros contatos do homem branco colonizador com os índios que aqui habitavam. Muitos sujeitos índios se deixaram dominar (escravizar), mas todo o processo de expansão e colonização/exploração do Brasil também se fez com focos de resistência indígena. Sabe-se, por exemplo, que na Bahia, mais especificamente em Ilhéus, a tribo dos Aimorés castigaram duramente os colonos portugueses. Houve aliança desses indígenas com os franceses, o que dificultou o processo de expansão da colonização portuguesa do Brasil. Há relatos de que uma das etnias mais resistentes, os Tapuias, eram bastante aguerridos o que levou os portugueses a conferir-lhes fama de sanguinários. Há também o caso de tribos que praticavam o ritual do antropofagismo como os tupinambás. Eles capturavam o inimigo e serviam sua carne como forma ritual de adquirir a força do mesmo. Todos esses fatos discursivizaram o povo indígena como selvagem e hostil desprovido de racionalidade e, também, objeto de grande temor. É esse o pré-construído que se agarrou à memória histórica que remonta ao tempo da colonização e até hoje habita o imaginário do brasileiro sobre o índigena e a potencial ameaça que ele representa.

Orlandi (1990) se ocupou em investigar os processos de sentido emergentes nas relações de contato entre diferentes culturas. Uma parte dessa pesquisa enfocou justamente o contado do branco europeu com o índio e a constituição da identidade brasileira que apaga o sujeito índio como seu outro. A autora observa processos de silenciamento ou apagamento do índio pelo Estado brasileiro. Esse apagamento se instala de diversas maneiras, a começar pelo próprio imaginário de como se deu a chegada dos exploradores portugueses: eles "descobriram" o Brasil ou encontraram uma porção de terra exuberante e exótica com o detalhe insignificante de haver selvagens "arredios" que precisavam ter seus corpos domesticados e suas almas salvas. 
Um longo processo de "pacificação" foi levado a cabo pelas autoridades brasileiras no sentido de resolver a "questão" indígena vista como um problema para o avanço e a colonização do interior brasileiro. À medida que esse processo avança para o interior, o índio luta com a força física/resiste e na FD do branco, segundo Orlandi (1990), a resistência indígena significa crime assim como seu autor é considerado criminoso. Produz-se no interior dessa FD uma divisão categorial dos índios em dois grupos, a saber, os índios tratáveis ou "civilizáveis" e os índios resistentes ou selvagens. Era preciso pacificar o índio, pois não havia remédio: ou era assimilado e aculturado/ "branqueado" ou era extinto/extirpado.

Quando voltamos nosso olhar para a história da colonização do Brasil, observamos, portanto, que os índios sempre resistiram à dominação do branco, à tomada de seus territórios. O gesto da índia se inscreve como um verdadeiro ritual de resistência, um ritual de interpelação ideológica sem falhas cujo efeito final é a defesa aguerrida do rio Xingu, este rio que cuja existência é condição sine qua non para a vida. Mas como se constata nas Sdr em análise, o discurso da mídia escrita tradicional trata de significar esse gesto a partir dos saberes que conformam o imaginário dominante na formação social do branco, a saber, como uma demonstração de selvageria e de incapacidade indígena para o diálogo.

\section{À guisa de conclusão}

Compreendemos que os locutores dessas narrativas jornalísticas, ao interpretar o gesto da índia, o fazem a partir de um lugar social inscrito na formação social capitalista e na formação cultural do branco que dá a ver o ritual da índia como produto de sua cultura menor, subdesenvolvida. Desta feita, esses sujeitos nunca entenderão o gesto da índia Tuíra como um ritual de resistência, dado que os índios, nessa perspectiva, são como animais sem logos, não são capazes de resistência política. Aqui, mais uma vez, Ranciére (1996) nos ajuda a pensar que o gesto midiático de interpretar a cena do facão aponta para o desentendimento, ou, o enxergar a resistência política da índia como algo da ordem do não ser, do impossível, da ordem da selvageria.

Este desentendimento que se processa pelo gesto de interpretação midiático abre sobre a imagem do índio selvagem e agressivo, do índio "não gente", do índio não tratável materializando-se na forma de enunciados que retornam sobre um conjunto de saberes já estabilizados na estrutura vertical. Desse modo, entendemos que as formulações que dão conta 
de significar o acontecimento histórico do I Encontro pela cena do gesto de Tuíra se inscrevem na ordem da repetibilidade, pois o discursivo retorna sobre e atualiza uma rede de enunciados pré-construídos que deram a ver o acontecimento pelo ângulo "transparente" da (re)ação indígena naturalmente agressiva e selvagem. Esse recorte do real com seu gesto de interpretação pelo viés da mídia escrita concorre para desqualificar a figura da índia (e junto com ela toda a nação Kayapó, bem como suas demandas), alçando-a ao status de vilã ou a agente de ações moralmente repreensíveis e até mesmo criminosas significadas pela expressão "quase cortando". Ao mesmo tempo em que desqualifica a índia, o discurso da mídia escrita alça as autoridades ao status de vítimas ou os pacientes que experimentaram o sentimento de constrangimento pela "ação abusiva" de Tuíra e de medo pelo iminente golpe certeiro da selvagem, tudo isso materializado por expressões como "apreensão" e "perplexidade".

\section{REFERÊNCIAS}

FERNANDES, Carolina. O imaginário de Veja sobre 'os Lulas presidenciáveis'. Dissertação de Mestrado. Instituto de Letras/UFRGS, Porto Alegre, RS, 2008

FERREIRA, Maria C.L. O lugar do social e da cultura numa dimensão discursiva. In:

INDURSKY, Freda; MITTMAN, Solange; FERREIRA, Maria C.L. Memória e história na/da análise do discurso. Campinas, SP: Mercado de Letras, 2011.

INDURSKY, Freda. A função enunciativa do porta-voz no discurso sobre o MST. Rio de Janeiro, Alea, v.2, n.2, p. 17-26, Ver. Do programa de Pós-Graduação em Letras neolatinas, UFRJ, set. 2000 Lula lá: estrutura e acontecimento. Organon (UFRGS), Porto Alegre, vol 17 n. 35, 2003, p. 101-121.

MAINGUENEAU, Dominique. Novas tendências em análise do discurso. Trad. Freda Indursky. Campinas: Pontes, 1989

MARIANI, B.S.C. O comunismo imaginário; práticas discursivas da imprensa sobre o PCB. Campinas, IEL, UNICAMP, 1996, p.64. Tese de doutorado.

ORLANDI, E. L. P. Terra à vista. Discurso do confronto: Velho e novo mundo. Campinas: Editora da Unicampi, 1990.

PÊCHEUX. Michel. (1983a) Discurso: Estrutura ou Acontecimento. $4^{\circ}$ ed. Campinas: Pontes, 2006.

(1975) Semântica e Discurso - Uma crítica à afirmação do óbvio. $4^{\text {o }}$ ed. Campinas: EDUNICAMP, 2009

(1983b) Papel da Memória. Tradução e introdução: José Horta Nunes. 3 ed. Campinas, SP: Pontes Editores, 2010. p.49-57.

RICARDO, Carlos Alberto. Povos Indígenas no Brasil: 1987/88/89/90. São Paulo: Cedi, 1981. p. 11-30. (Aconteceu Especial, 18).

RANCIERE, Jacques. O desentendimento. São Paulo, Ed. 34, 1996.

SILVEIRA, Cristina Cattaneo da. Interpretação e decisão: uma análise discursiva do julgamento sobre a delimitação da reserva indígena Raposa do Sol. Porto Alegre, 2010. 191f. Dissertação (Mestrado em Letras) - Universidade Federal do Rio Grande do Sul, 2010. 
SOUZA, Pedro de. Acidente ou ataque? Leitura de imagens e imagens de leitura. Signos, ano 22, p. 7-20, 2001.

ZIZEK S. Como Marx Inventou o Sintoma?. In: Um mapa da ideologia. Rio de Janeiro: Contraponto, 1999.

Recebido em 23/05/2020. Aceito em 28/06/2020. 